\title{
Changes in speed near the onset of Bindschadler Ice Stream, West Antarctica
}

\author{
J. Paul WINBERRY, ${ }^{1}$ Sridhar ANANDAKRISHNAN, ${ }^{1}$ Andrew M. SMITH ${ }^{2}$ \\ ${ }^{1}$ Center for Remote Sensing of Ice Sheets and Department of Geosciences, The Pennsylvania State University, University Park, \\ Pennsylvania, PA 16802-7501, USA \\ E-mail: winberry@essc.psu.edu \\ ${ }^{2}$ British Antarctic Survey, National Environment Research Council, Madingley Road, Cambridge CB3 OET, UK
}

\begin{abstract}
Ice-stream velocities can change rapidly. Understanding the spatial and temporal pattern of these changes and the forcings responsible is essential for predicting ice-sheet mass balance. Inland migration of the onset location will lead to more efficient drainage of inland ice. One way to monitor the stability of the onset location is to investigate changes in the velocity field. We report on the velocity near the onset of Bindschadler Ice Stream, West Antarctica, in 2002 and compare these data to the velocity measured in 1996. Mean annual velocities were determined by measuring the GPS position of markers during consecutive seasons. We compare our results with similar measurements from 1996 to investigate temporal changes in this ice-stream onset. Our results indicate that only minimal changes have occurred in the speed of the ice stream between 1996 and 2002.
\end{abstract}

\section{INTRODUCTION}

Since Mercer (1968) made the initial proposal that catastrophic collapse of the West Antarctic ice sheet (WAIS) could lead to rapid sea-level rise, significant work has been undertaken to understand the stability of the WAIS. Much of this work has focused on the fast-flowing ice streams that drain the interior of the ice sheet. In contrast to inland ice, which moves primarily by internal deformation at relatively low speeds of $10-20 \mathrm{~m} \mathrm{a}^{-1}$, the WAIS ice streams obtain speeds of $100-1000 \mathrm{~m} \mathrm{a}^{-1}$ due to rapid basal motion that results from enhanced lubrication (Alley and others, 1986; Blankenship and others, 1986). Understanding the conditions leading to the formation of ice streams is essential to predicting the dynamics of the WAIS and its future contribution to sea-level rise.

Of particular importance are the dynamics at the onset region of ice streams. The onset location marks the transition between an inland-flow regime and a streaming-flow regime (Bindschadler and others, 2001) and serves as the primary conduit by which inland ice is fed into the ice streams. Several workers have suggested that the current configurations of ice streams in the WAIS lead to unstable onset locations and that inland migration is likely occurring at rates $>200 \mathrm{~m} \mathrm{a}^{-1}$ (Bindschadler, 1997; Price and Whillans, 2001). Inland migration of an ice-stream onset would allow an ice stream to more easily drain the large reservoir of ice that resides upstream of the onset, increasing the volume of ice that can be can discharged into the world's oceans.

While the onsets of ice streams exert fundamental control on the long-term evolution of the WAIS, the dynamics controlling onset location remain unclear. Hypotheses on controls of onset location have emphasized the role of subglacial geologic and topographic conditions as well as glaciological mechanisms. The importance of geology and topography in the onset of ice streaming has evolved from geophysical studies that have demonstrated that the upstream reaches of ice streams appear to reside in deep subglacial troughs (Anandakrishnan and others, 1998; Bell and others, 1998; Joughin and others, 1999; Studinger and others, 2001). Detailed seismic work in several locations has revealed that these troughs are filled with large volumes of sediments, suggesting that ice-stream locations are restricted to regions where abundant subglacial sediments are present (Anandakrishnan and others, 1998; Peters and others, 2006). However, the mere presence of sediments is insufficient for streaming conditions to exist. Abundant subglacial water is also required in order to weaken the shear strength of subglacial sediments. The importance of subglacial water suggests that the distribution of basal meltwater and potential feedbacks between basal sliding and basal melting are also critical factors in determining the locations of icestream onsets (Price and others, 2002).

Fundamental to unraveling the mechanics of ice-stream onsets are observations that provide insight into their temporal behavior. While a significant number of studies have documented the annual to decadal behavior in the trunks of ice streams (e.g. Alley and Whillans, 1991; Retzlaff and Bentley, 1993), observations near the onset remain limited (e.g. Price and Whillans, 2001). Given the rapid timescales at which ice streams may adjust their velocities, monitoring the velocity of an ice stream over a period of a few years will provide insight into onset dynamics. In order to investigate the stability of the flow field of Bindschadler Ice Stream (BIS; former Ice Stream D), West Antarctica, we compare two velocity datasets that are separated by 6 years.

\section{THE ONSET OF BINDSCHADLER ICE STREAM}

BIS is one of the five major ice streams that drain the WAIS into the Ross Ice Shelf (Fig. 1). Like all ice streams of the WAIS, BIS is fed by a long tributary that flows in a deep subglacial sedimentary basin (Joughin and others, 1999; Peters and others, 2006) extending inland towards the ice divide (Hodge and Doppelhammer, 1996; Joughin and others, 1999). While tributaries may attain speeds more than an order of magnitude faster than surrounding inland ice, their speeds remain significantly lower than those found in the main trunk of the ice stream (Joughin and others, 1999). The mechanics controlling flow of an ice-stream tributary appear to be fundamentally different than those 


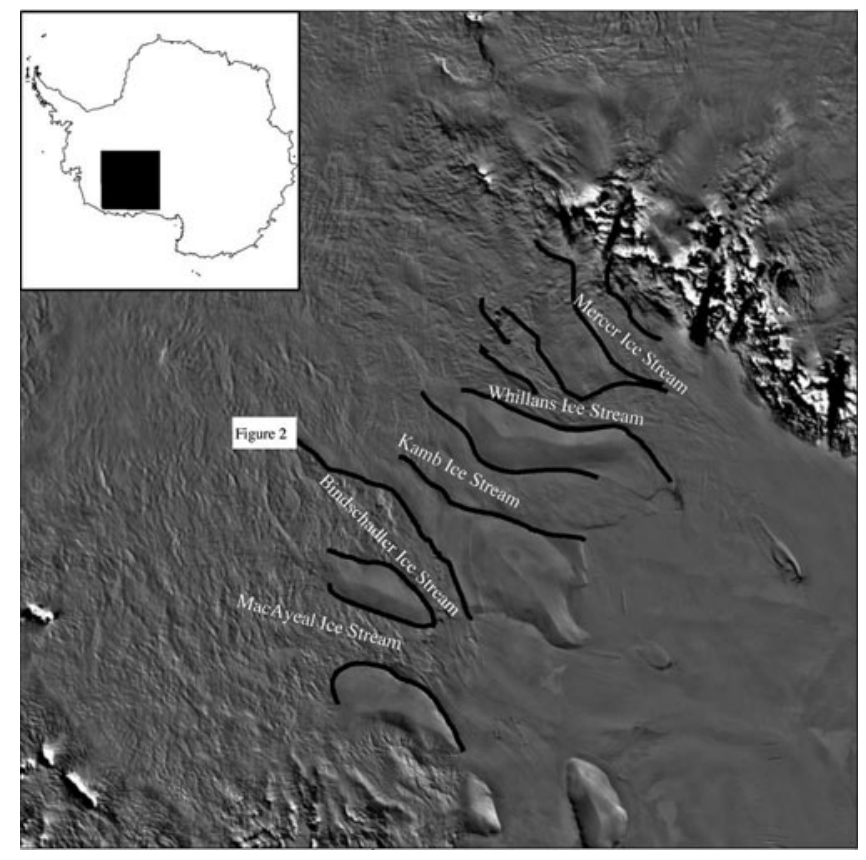

Fig. 1. MODIS mosaic of West Antarctica (T. Haran and others, http://nsidc.org/data/moa/). The major ice streams that drain the WAIS interior are labeled. Location of study region is shown in the white box.

that control flow in the main trunk of the ice stream. Observed velocities in tributaries are directly proportional to driving stress, and basal drag is a dominant force resisting motion, indicating that internal deformation of the ice sheet contributes significantly to motion (Bindschadler and others, 2000). In contrast, the movement of ice streams is dominated by basal motion and resisted primarily by lateral drag, resulting in an inverse relationship between driving stress and velocity in the main body of the ice stream. Bindschadler and others (2000) used measurements of ice thickness and bedrock elevation to calculate driving stress near the onset of BIS. When these were coupled with observations of surface velocity, they were able to locate the onset of BIS by identifying the transition from tributary- to streaming-flow regimes (star in Fig. 2b). Force-balance analysis showed velocity near the onset rapidly increases (Fig. 2) in response to rapid reduction in basal drag, to $\approx 0$, also indicating a transition from tributary flow to streaming flow (Price and others, 2001, fig. 7) at the onset identified by Bindschadler and others (2000).

Bindschadler and others (2001) have suggested that, based on mass continuity arguments, the onset location of BIS is unstable and should be migrating inland at rates up to $400 \mathrm{~m} \mathrm{a}^{-1}$. Essential for this inland migration of the icestream onset into its tributary is the presence of a significant basal water system to allow efficient basal lubrication of the tributary. Recent observations have imaged an active basal water system near the onset of BIS. The diamonds in Figure $2 \mathrm{~b}$ are the locations of rapid, <24 days, interferometric synthetic aperture radar (InSAR) imaged surface elevation changes that have been interpreted as the transport of a large volume of subglacial water (Gray and others, 2005). In addition, Peters and others (2007) have directly imaged a large pool of water in the region using seismic methods.

\section{CHANGES IN SPEED NEAR THE ONSET OF BINDSCHADLER ICE STREAM}

If inland migration of an ice stream is occurring, the velocity field should be changing over time, so we hypothesize that speeds upstream of the ice-stream onset should be increasing. To address whether inland migration of the BIS onset is occurring, we compared two datasets of mean annual velocity measured in 1996 and 2002, respectively.

The baseline dataset is that of Bindschadler and others (2000), collected during the 1995/96 and 1996/97 field seasons. This campaign measured velocities on a $160 \mathrm{~km}$ by $60 \mathrm{~km}$ grid with $5 \mathrm{~km}$ spacing that covered the majority of the main tributary feeding BIS. Errors for this dataset are $0.12 \mathrm{~m} \mathrm{a}^{-1}$, and the details of data collection and processing can be found in Chen and others (1998).

We collected a second set of velocity measurements during the 2001/02 and 2002/03 field seasons. Our experiment spanned a $40 \mathrm{~km}$ region covering the transition from tributary to ice-stream flow and consisted of one longitudinal profile and several transverse lines. The most upstream transverse profile is located $\approx 30 \mathrm{~km}$ upstream of the onset, where velocities of $\approx 60 \mathrm{~m} \mathrm{a}^{-1}$ were measured along the center flowline of the tributary in 1996. Typical of tributary flow, motion at this location is significantly resisted by basal drag (Price and others, 2001, fig. 7). The four downstream transverse profiles cover the transition from tributary flow to ice-stream flow observed by Bindschadler and others (2000).

In total, 58 stakes were deployed during the 2001/02 season and resurveyed the following season, providing an average velocity for 2002. Data were recorded using Trimble dual-frequency receivers sampling every $30 \mathrm{~s}$. Data were collected in a static mode with a rover to base-station baseline of no greater than $20 \mathrm{~km}$. The base station was left at a central location, while a snowmobile was used to transport the rover unit to stake locations for 20-45 min. Stake positions were calculated from baseline solutions between the stake location and the base station, resulting in horizontal errors of $<0.20 \mathrm{~m}$. The results of our measurements are plotted along with the results of Bindschadler and others (2000) in Figure 2a. The velocity fields from both years show a similar pattern of converging flow from the north and south into the tributary of the ice stream.

The goal of this study is to investigate the temporal stability of the onset location of BIS by investigating possible changes in speed in the onset region of BIS between 1996 and 2002. However, the two datasets did not measure velocities at the same locations. Our 2002 data were embedded inside the 1996 grid at a locally higher resolution of approximately $2.5 \mathrm{~km}$ vs the 1996 spacing of $\approx 5 \mathrm{~km}$. For this reason, interpolation was necessary to obtain a velocity pair for comparison between 1996 and 2002. Since the 1996 data were collected on a regularly spaced grid, we used a cubic interpolation method to estimate the 1996 velocity at the locations of 2002 stakes. The interpolated values were then used to calculate the changes in speed between 1996 and 2002. Four 2002 measurements were not used in the study as they were outside the 1996 grid.

Given the large gradients present in the the velocity field of ice streams and the relatively coarse grid of Bindschadler and others (2000), the interpolation will introduce errors in our estimates of 1996 velocities at the 2002 stake locations. These errors will be smaller near the center line of the ice 

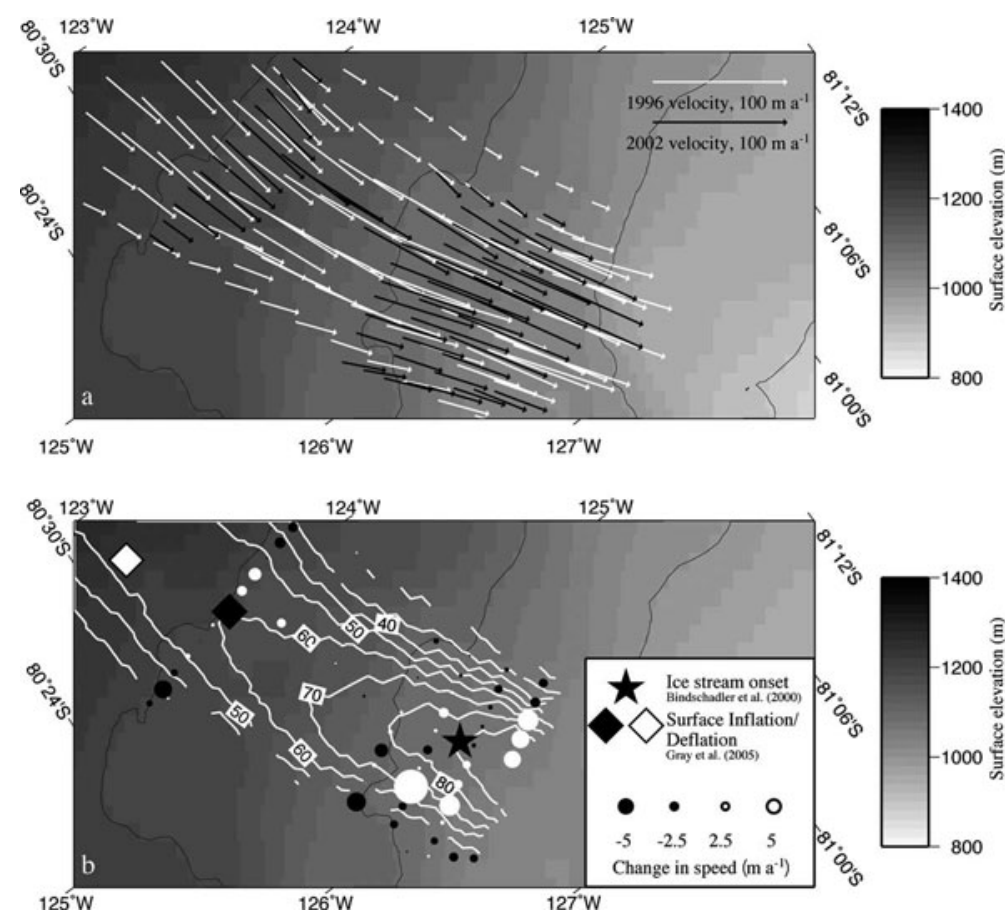

Fig. 2. Surface elevation map of the region highlighted in Figure 1 (Blankenship and others, 2001). (a) Velocity field from both 1996 (white) and 2002 (black). (b) The interpolated changes in speed between 1996 and 2002. Dots indicate the locations of 2002 ice velocity measurements; size and color of the symbol indicates change in speed between 1996 and 2002. White contours are surface speeds derived from the 1996 grid of Bindschadler and others (2000). Star indicates the onset of BIS (Bindschadler and others, 2000). Black and white diamonds are the inflation and deflation respectively of Gray and others (2005).

stream, where velocity gradients are typically small, and larger at the margins where significant velocity gradients are found. We used a theoretical ice-stream cross-sectional velocity model (equation 5.5.14 of Van der Veen, 1999) to assess the magnitude of these interpolation errors. We first computed a suite of velocity profiles for ice streams at a resolution of $5 \mathrm{~km}$ (resolution of the 1996 dataset) of width $30 \mathrm{~km}$ (the width of BIS in the onset region) using center-line velocities similar to those found in our study area of 60 $100 \mathrm{~m} \mathrm{a}^{-1}$. We then used these coarsely sampled profiles to interpolate at a $1 \mathrm{~km}$ resolution along the width of the theoretical ice stream. These interpolated values were then compared with the 'perfect' results predicted by the model at those locations to assess errors introduced by the interpolation. As expected, near the center of the ice stream the interpolation works well, producing differences of $<0.05 \mathrm{~m} \mathrm{a}^{-1}$ between the interpolated and theoretical predictions for all models. Additionally, as expected, the interpolation does poorly near the margins, where the mismatch between the theoretical and interpolated values can be as large as $2.5 \mathrm{~m} \mathrm{a}^{-1}$. For this reason, when interpreting changes in ice-stream velocity, center-line stake locations will provide the most robust indicators of change.

Observed changes in speed were typically small, with a mean change of $0.1 \mathrm{ma}^{-1}$, with a standard deviation of $3.7 \mathrm{~m} \mathrm{a}^{-1}$, between 1996 and 2002 (Fig. 3). As discussed above, measurements from within the center of the ice stream will provide the most reliable estimates of changes in velocity. Center-line velocities typically exhibit small changes of $<1 \mathrm{ma}^{-1}$ (Fig. 2b) along the length of our study area. Near the shear margins, a few locations exhibited larger changes in velocity of $>5 \mathrm{~m} \mathrm{a}^{-1}$. However, these larger changes display no spatial continuity as would be expected of real changes in ice-stream velocity. Stations near those that have large velocity changes exhibit either small changes or changes of opposite sign. In addition, these sites tend to be located in regions with large longitudinal velocity gradients, further reducing confidence in the ability to accurately interpolate at these sites. Thus, we conclude that the large changes in speed observed at stations near the ice-stream margin are contaminated by interpolation errors. Taken as group, the results from the entire study area indicate only minimal changes occurred across the onset region.

\section{DISCUSSION}

Inland migration of WAIS ice streams is predicted by both theoretical and field-based studies, suggesting the velocity field near the onset region should be experiencing rapid

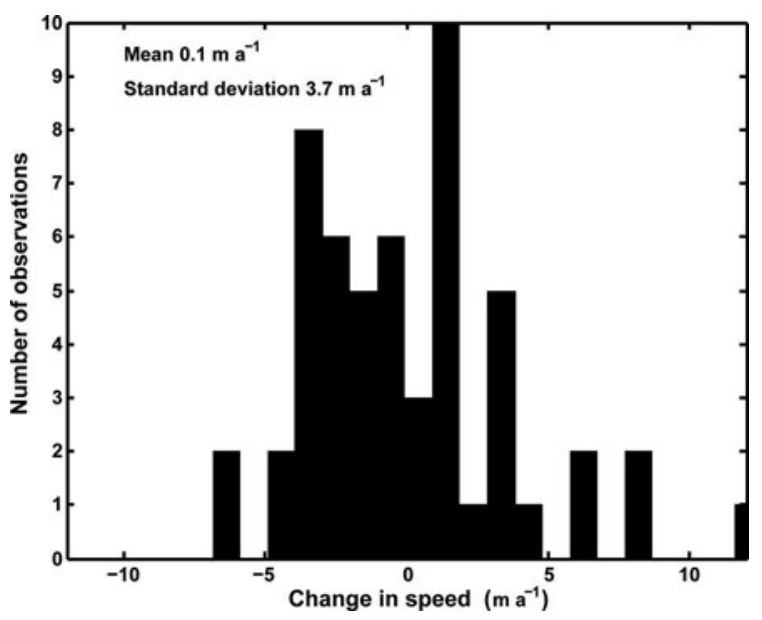

Fig. 3. Distribution of results. 
change. If the onset of the ice stream is migrating inland, it would be expected that high speeds should be propagating upstream. Our repeat measurements will be most sensitive to an inland migration near the onset, where the largest longitudinal gradients $\left(S_{\mathrm{G}}\right)$ in speed are present. Near the onset of BIS, $S_{\mathrm{G}}$ can be as large as $2 \mathrm{~m} \mathrm{a}^{-1} \mathrm{~km}^{-1}$. Thus, for inland migration rates $\left(M_{R}\right)$ of 200 and $400 \mathrm{~m} \mathrm{a}^{-1}$, estimated changes in speed during the 6 year separation of the two measurements $\left(S_{\mathrm{G}} \times M_{\mathrm{R}} \times \Delta t\right)$ are 2.4 and $4.8 \mathrm{~m} \mathrm{a}^{-1}$, respectively. Our temporal baseline is too short to resolve the difference between a stable onset region and one migrating inland at $200 \mathrm{~m} \mathrm{a}^{-1}$. However, a rapid inland migration rate of $400 \mathrm{~m} \mathrm{a}^{-1}$ would result in an increased velocity of $\approx 5 \mathrm{~m} \mathrm{a}^{-1}$ that would be discernible by our measurements. Thus, our results indicate that if inland migration is occurring, it is doing so at a rate $<400 \mathrm{~m} \mathrm{a}^{-1}$. We cannot rule out future rapid migration of BIS onset, as several authors have suggested that inland migration of ice streams is an episodic process (Whillans and others, 1987; Price and Whillans, 2001). If this is the case, the onset of BIS may currently be in a period of stability, similar to what Whillans Ice Stream experienced in the 1950s before continued inland migration (Price and Whillans, 2001). For this reason, future observations of velocity in the onset region of BIS are required to determine the stability of the basal water system upstream of the BIS onset. However, our results indicate the velocity of the icestream onset remained unchanged during this period, implying the dynamic water system that underlies the tributary of BIS remains unable to efficiently lubricate the bed upstream of the BIS onset and promote inland migration of the ice stream.

\section{ACKNOWLEDGEMENTS}

This work was supported the US National Science Foundation's Office of Polar Programs and the Center for Remote Sensing of Ice Sheets. We thank all those involved in the 2001/02 and 2002/03 Onset D field parties, the University Navstar Consortium and Raytheon Polar Services for support in the field. We also thank A. Huerta for comments on an early draft, and G. Catania and an anonymous reviewer for suggestions. Data from 1996 were obtained from the US National Snow and Ice Data Center.

\section{REFERENCES}

Alley, R.B. and I.M. Whillans. 1991. Changes in the West Antarctic ice sheet. Science, 254(5034), 959-963.

Alley, R.B., D.D. Blankenship, C.R. Bentley and S.T. Rooney. 1986. Deformation of till beneath Ice Stream B, West Antarctica. Nature, 322(6074), 57-59.

Anandakrishnan, S., D.D. Blankenship, R.B. Alley and P.L. Stoffa. 1998. Influence of subglacial geology on the position of a West Antarctic ice stream from seismic observations. Nature, 394(6688), 62-65.

Bell, R.E. and 6 others. 1998. Influence of subglacial geology on the onset of a West Antarctic ice stream from aerogeophysical observations. Nature, 394(6688), 58-62.
Bindschadler, R. 1997. Actively surging West Antarctic ice streams and their response characteristics. Ann. Glaciol., 24, 409-414.

Bindschadler, R., X. Chen and P. Vornberger. 2000. The onset area of Ice Stream D, West Antarctica. J. Glaciol., 46(152), 95-101.

Bindschadler, R., J. Bamber and S. Anandakrishnan. 2001. Onset of streaming flow in the Siple Coast region, West Antarctica. In Alley, R.B. and R.A. Bindschadler, eds. The West Antarctic ice sheet: behavior and environment. Washington, DC, American Geophysical Union, 123-136. (Antarctic Research Series 77.)

Blankenship, D.D., C.R. Bentley, S.T. Rooney and R.B. Alley. 1986. Seismic measurements reveal a saturated porous layer beneath an active Antarctic ice stream. Nature, 322(6074), 54-57.

Blankenship, D.D. and 9 others. 2001. Geologic controls on the initiation of rapid basal motion for West Antarctic ice streams: a geophysical perspective including new airborne radar sounding and laser altimetry results. In Alley, R.B. and R.A. Bindschadler, eds. The West Antarctic ice sheet: behavior and environment. Washington, DC, American Geophysical Union, 105-121. (Antarctic Research Series 77.)

Chen, X., R.A. Bindschadler and P.L. Vornberger. 1998. Determination of velocity field and strain-rate field in West Antarctica using high precision GPS measurements. Surv. Land Inf. Syst., 58(4), 247-255.

Gray, L., I. Joughin, S. Tulaczyk, V.B. Spikes, R. Bindschadler and K. Jezek. 2005. Evidence for subglacial water transport in the West Antarctic Ice Sheet through three-dimensional satellite radar interferometry. Geophys. Res. Lett., 32(3), L03501. (10.1029/2004GL021387.)

Hodge, S.M. and S.K. Doppelhammer. 1996. Satellite imagery of the onset of streaming flow of Ice Streams C and D, West Antarctica. J. Geophys. Res., 101(C3), 6669-6677.

Joughin, I. and 7 others. 1999. Tributaries of West Antarctic ice streams revealed by RADARSAT interferometry. Science, 286(5438), 283-286.

Mercer, J.H. 1968. Antarctic ice and Sangamon sea level. IASH Publ. 79 (General Assembly of Bern 1967 - Snow and Ice), 217-225.

Peters, L.E. and 6 others. 2006. Subglacial sediments as a control on the onset and location of two Siple Coast ice streams, West Antarctica. J. Geophys. Res., 111(B1), B01302. (10.1029/ 2005JB003766.)

Peters, L.E., S. Anandakrishnan, R.B. Alley and A.M. Smith. 2007. Extensive storage of basal meltwater in the onset region of a major West Antarctic ice stream. Geology, 35(3), 251-254.

Price, S.F. and I.M. Whillans. 2001. Crevasse patterns at the onset to Ice Stream B, West Antarctica. J. Glaciol., 47(156), 29-36.

Price, S.F., R.A. Bindschadler, C.L. Hulbe and D.D. Blankenship. 2002. Force balance along an inland tributary and onset to Ice Stream D, West Antarctica. J. Glaciol., 48(160), 20-30.

Retzlaff, R. and C.R. Bentley. 1993. Timing of stagnation of Ice Stream C, West Antarctica, from short-pulse radar studies of buried surface crevasses. J. Glaciol., 39(133), 553-561.

Studinger, M., R.E. Bell, D.D. Blankenship, C.A. Finn, R.A. Arko and D.L. Morse. 2001. Subglacial sediments: a regional geological template for ice flow in West Antarctica. Geophys. Res. Lett., 28(18), 3493-3496.

Van der Veen, C.J. 1999. Fundamentals of glacier dynamics. Rotterdam, etc., A.A. Balkema Publishers.

Whillans, I.M., J. Bolzan and S. Shabtaie. 1987. Velocity of Ice Streams B and C, Antarctica. J. Geophys. Res., 92(B9), 8895-8902. 